10.31341/jios.45.2.11

UDC 001.891:001.895:378(497.4)

OOpen Access

Survey Paper

\title{
Differences in Personal Innovativeness in the Domain of Information Technology Among University Students and Teachers
}

\author{
Andrej Šorgo \\ andrej.sorgo@um.si \\ Faculty of Natural Science and Mathematics \\ Faculty of Electrical Engineering and Computer Science \\ University of Maribor, Maribor, Slovenia \\ Mateja Ploj Virtič \\ Faculty of Natural Science and Mathematics \\ University of Maribor, Maribor, Slovenia \\ mateja.plojvirtic@um.si \\ Kosta Dolenc \\ kosta.dolenc@um.si \\ Faculty of Education \\ University of Maribor, Maribor, Slovenia
}

\begin{abstract}
Two online surveys among 1105 university students and 656 employees were conducted with the inclusion of the construct Personal Innovativeness in the domain of Information Technologies (PIIT). After calculating descriptive statistics, statistically significant differences between personal innovativeness of university students and teachers were sought by the application of one-way ANOVA. The first and most important finding was that average perceived PIIT of teachers and students falls around the middle of the seven-point scale, which cannot be regarded as a plausible predictor of upgrading the University as an Innovative Ecosystem. The second was that university teachers scored higher than their students, a situation that could produce an expectancy conflict between those who want to work in an innovative way and those who would prefer study by the book. Teaching assistants, who should belong to the generation of digital natives, are only slightly more innovative than university teachers, who can be regarded as digital immigrants. Assuming that innovativeness can be upgraded by learning, means that efforts should be made by University Management to encourage and support Personal Innovativeness (and other creativities, as well) as a preferred teaching practice.

Keywords: Personal Innovativeness, Information Technologies, University students, University teachers, Online education
\end{abstract}

\section{Introduction}

Innovativeness and creativity accompanied by information and digital literacy are recognized by many as paramount factors leading toward solutions to the problems of 
modern civilization. Therefore, any society, company and institution that wants to solve problems, create new products, or invent new processes needs a surplus of creative people who think and work creatively and develop a culture of innovation and creativity $[1,2,3]$. Importance of creativity and innovativeness is well recognized and established as a norm in art, architecture, design, entertainment, and fashion, as examples [4], and new ways of partnership between human and machine creativity are searched [5]. Even if creativity and innovation are named in documents of practically all international organizations oriented toward future [6] operationalization of creativity as an individual and organizational effort is an open-ended challenge $[7,8,9]$.

Nowadays, universities have two major roles. In the first role, universities should be generators of innovations based on creative processes, a demand which calls for highly innovative employees. Their second role is as provider of educated citizens to supplement and replace employees in all sectors, from culture to civil engineering, and be able to infuse innovation into their daily work routines, a role that calls for creative students and employees. Therefore, in an ideal world, universities will be the intellectual playgrounds of communities of teachers and students creating novel ideas, concepts, processes, and products. However, someone cannot just write in a declaration that universities are "Innovative ecosystems" [10]; instead, universities must begin to develop infrastructure, along with the personnel to use it, and develop a culture where it is important to be innovative not only in research but in pedagogy and in the application of innovative pedagogical principles, whether or not through the use of digital technologies.

There exist different views and descriptions of creativity and of innovativeness as a concomitant part. Views from one of the extremes are that creativity is just a manifestation of intelligence [11]. At the other end are opinions about the existence of different kinds of creativity [12,13] and claims that creativity can be taught [14]. For practical reasoning, someone should distinguish between creativity as a personal characteristic or trait and the willingness to adopt an innovative process or tool to be used for solving problems or creating goods [15]. In the words of Ballor and Claar [16] "Creativity can be understood as what human beings do in connection with the fundamental givenness of things. Innovation, on the other hand, can be best understood as a phenomenon related to the historical progress of humankind".

In recent decades, digital technology has become ubiquitous in such quantity and scope that some authors have tagged those persons born in the digitally rich world as digital natives [17], believing that immersion in digitally rich environments suffices to be able to use it. The concept has been challenged and recognized as an urban myth [18], and on many occasions, it has been shown that intensive use of technology may improve self-efficacy, manipulative skills, and experience, but not, for example, information literacy or the ability to use retrieved information [19]. The connection between general creativity and adoption and adaptation of a specific digital application or program is not well established. On the other hand, studies applying the construct connecting Personal Innovativeness in the domain of Information Technology (PIIT), as defined by [20], are numerous. It is beyond the scope of the 
current paper to review these studies, nor the different methods for measuring innovativeness and creativity in all its diversity [21].

\section{Theoretical Framework and Hypotheses}

The purpose of this paper is to explore differences in PIIT among university students and teachers. The arguments justifying such research are that more innovative students and their educators will apply innovative technology in an earlier adoption phase, which can be regarded as an advance because such pioneers can work as agents of change $[15,20]$.

The researchers [22] continued the effort to explore the nature of influences from personal innovativeness over information systems and technology adoption. They recognized that highly innovative individuals are active seekers of information about new ideas and can cope with high levels of uncertainty and thus develop more positive intentions toward acceptance.

Recent literature regarding the construct PIIT is mainly focused on using it as a construct in the following areas:

- explaining continuance intentions for the usage of Mobile Web 2.0 learning [23];

- readiness for the adoption of Mobile learning [24];

- behavioural intention to use Mobile learning [25];

- behavioural intention, use behaviour and the acceptance of electronic learning systems [15].

However, potential conflicts between teachers and their students regarding the innovative use of information technology could emerge. As described in [26], innovative teachers can encounter innovative students, a situation which can optimally result in fruitful cooperation and high-level intellectual outcomes. In cases where teachers are innovative and expect innovativeness from non-innovative students, such a relation can create stress in both partners. However, students can be forced to learn the use of some cutting-edge technologies. When innovative students meet noninnovative teachers, such teachers can be recognized as boring, a perception which can result in absenteeism and working at the minimum standard with outdated technologies to fulfil the obligations. The situation where non-innovative teachers met non-innovative students is, paradoxically, the situation without conflict; both partners easily negotiate what is necessary for peaceful coexistence because the unexpected as an integral part of innovation is eliminated.

Based on the aims of the study, two research questions were formed:

- Is there a difference between university students and teachers in Personal Innovativeness in adoption of and experimentation with information technology?

- Is there a difference between university teachers and their teaching assistants in Personal Innovativeness in adoption of and experimentation with information technology? 
- Differences based on personal and socio-demographic traits and characteristics are without doubt interesting, however, mostly irrelevant for introduction of innovative and creative practices in the educational process based on equality and non-discriminative university standards. Therefore, they were not explored and are not reported.

\section{Methodology}

\subsection{Sampling Procedure}

Two different online forms were created for the purpose of the larger studies by the open-source application for web surveys [27] (1KA). The Personal Innovativeness scale formed part of both studies. The link was announced to University teachers through their institutional e-mail. Students were accessed by using a range of access channels, such as social networks and Faculty mailing lists. The instrument was anonymous, and response was considered as consent. An opt-out option was recognized in the fact that no fields were marked as obligatory, and that no participant would be subject to abuse or benefits from responding. After the introductory page giving the reasons for and authorship of the survey, respondents were obliged to tick agreement before entering the survey. According to the University rules, such research does not need the approval of an ethical body, because no sensitive personal data was collected.

\subsection{Research Population and Sample}

The research population consisted of Slovene-speaking university students and teachers from the University of Maribor, Slovenia (hereinafter students and teachers). The University of Maribor has 19 members (17 faculties, the University Library and the Student Dormitories) and is the second largest and second oldest university in Slovenia. Based on the University of Maribor's annual 2019 program, the total number of students was 13,337 in this year, and the entire population of higher education teachers numbers 598, and higher education associates 316 . It is an autonomous, scientific-research and educational institution in the fields of humanities, social sciences, engineering, economics, medicine, natural sciences, law, pedagogical sciences, and the arts.

We received responses about the PIIT construct from 624 employees and 1105 students (Table 1). Out of employee's population $422(65.7 \%)$ declared themselves as university teachers, $152(24.4)$ as teaching assistants, and $48(7.7 \%)$ declared as other or data were missing. 


\begin{tabular}{llllll} 
& N & Males & Females & Other & $\begin{array}{l}\text { Not } \\
\text { provided }\end{array}$ \\
\cline { 2 - 6 } Teachers & 624 & 332 & 298 & $4(0.6 \%)$ & $4(0.6 \%)$ \\
Students & 1105 & $\begin{array}{l}(49,1 \%) \\
197\end{array}$ & $\begin{array}{l}(45.4 \%) \\
773\end{array}$ & $2(0.2 \%)$ & 173 \\
& & $(17.8 \%)$ & $(66.3 \%)$ & & $(15,7 \%)$ \\
\hline
\end{tabular}

Table 1. Gender of the research population.

Given the high response rate, we can accept that the samples are representative for the populations of interest furthermore in all the papers reviewed (see Table 3), the sample population varies from less than 100 to 300 . The sample population is limited to the institution or to the users of the service under study. In our study, we included more than $60 \%$ of all employed university teachers and teaching assistants and $8 \%$ of all students. Therefore, the representativeness of our sample is confirmed.

\subsection{Description of the Construct}

Agarwal \& Prasad [15] define Personal Innovativeness in the domain of information technology (PIIT) as, "the willingness of an individual to try out any new information technology." The construct was later used in numerous studies, showing appropriate reliability and unidimensionality in different contexts [22,28,29].

Personal innovativeness is recognized by many researchers $[30,31,32,33]$ as an important construct in understanding new information systems and technology diffusion and usage intentions.

The construct in our studies is assembled from three of the four items on the original scale (see Figure 1). The statements can be evaluated on a 7-point format from completely disagree (1) to completely agree (7).

\subsection{Statistical Procedures}

Statistical analyses follow traditional methods as applied in verifying the differences between groups of persons [34]. Beforehand, all items were checked for missing data and data of them who did not respond to the items of interest were excluded from the calculations. Procedures of descriptive statistics were used for investigating the frequency distribution and calculation of central tendencies (Arithmetic Mean, Standard Deviation, Mode and Median). With the application of Principal Component Analysis, constructs were checked for unidimensionality. Results of KMO and Bartlett's tests show that matrices are appropriate to proceed with PCA. Values of KMO for matrix of student's data is .725 and for teachers .717. Values of Barlett's test are Chi-square $=1656 ; d f=3 ; p<.001$ ) for matrix of student and Chi-square = $1145 ; d f=3 ; p<.001)$ for matrix of teachers, respectively. These values are above thresholds as recommended in references [34]. Cronbach's alphas were calculated to assess the reliability of the constructs. As a threshold margin for Cronbach's alphas $>$ .70 was set. Statistically significant differences were sought by the application of oneway ANOVA. When two means were compared effect sizes are provided as Cohen's 
$d$ for unequal samples interpreted as no effect $(<0.2)$, small effect $(<0.5)$, intermediate effect $(<0.8)$, and large effect $(>0.8)$ within $95 \%$ confidence intervals (CI) [35].

\section{Findings}

\subsection{Figures and Tables}

From the results presented in Table 1, it is evident that the means of answers on all items of both groups lie in a range of plus or minus one point around the middle of the scale, which indicates only a mediocre PIIT. However, the tendency is for students to fall below the midpoint, while teachers fall above the midpoint. Being below the midpoint indicates disagreement with a statement showing higher PIIT for teachers, while being above shows agreement with the statement. In terms of effect sizes and according to Cohen's interpretation [35], two effect sizes fall on the border between small and medium, and one in the range of small effect sizes.

\begin{tabular}{|c|c|c|c|c|c|c|c|c|c|c|c|c|c|c|c|}
\hline & & \multicolumn{6}{|c|}{ Teachers } & \multicolumn{6}{|c|}{ Students } & \multicolumn{2}{|c|}{ Effect sizes } \\
\hline & & $\mathrm{N}$ & Mean & SD & Med & Mode & $\mathrm{CL}$ & $\mathrm{N}$ & Mean & SD & Med & Mode & $\mathrm{CL}$ & $d$ & $\mathrm{CI}$ \\
\hline PIIT1 & $\begin{array}{l}\text { If I heard about new information technology, I } \\
\text { would look for ways to experiment with it. }\end{array}$ & 656 & 4.91 & 1.72 & 5 & 7 & .86 & 1105 & 4.03 & 1.79 & 4 & 4 & .86 & 0.50 & $\begin{array}{l}.40- \\
.60\end{array}$ \\
\hline PIIT2 & $\begin{array}{l}\text { Among my peers, I am usually the first to try } \\
\text { out new information technology. }\end{array}$ & 654 & 4.26 & 1.76 & 4 & 4 & .91 & 1102 & 3.44 & 1.83 & 3 & 4 & .90 & 0.51 & $.41-$ \\
\hline PIIT3 & $\begin{array}{l}\text { I like to experiment with new information } \\
\text { technology. }\end{array}$ & 652 & 4.51 & 1.86 & 5 & 4 & .93 & 1105 & 3.82 & 1.91 & 4 & 4 & .91 & 0.36 & $.27-.45$ \\
\hline & $\%$ of variance & & & & & & 81.2 & & & & & & 79.1 & & \\
\hline & Eigenvalue & & & & & & 2.44 & & & & & & 2.37 & & \\
\hline & Cronbach's alpha & & & & & & .88 & & & & & & .87 & & \\
\hline
\end{tabular}

Figure 1. Differences between university teachers and university students in Personal Innovativeness in the Domain of Information Technology.

This allows us to conclude that teachers perceive themselves as more personally innovative in the domain of information technology than students. The differences cannot be taken lightly because many students may perceive tasks and assignments that include innovativeness and creativity as too demanding. On the other hand, one should expect university educators to be recruited among the most innovative part of the population, but it seems that this is generally not the case.

\begin{tabular}{cllllllc} 
& & $\mathrm{N}$ & Mean & SD & F & $p$ & Cohen's $d$ \\
\hline \multirow{2}{*}{ PIIT1 } & Teachers & 424 & 4.86 & 1.791 & & & 0.27 \\
& Assistants & 152 & 5.32 & 1.467 & 7.905 & .005 & CI $=0.08-0.46$ \\
& Total & 576 & 4.98 & 1.722 & & & 0.28
\end{tabular}




\begin{tabular}{clrrrrrc} 
& Assistants & 152 & 4.71 & 1.499 & & CI $=0.09-0.47$ \\
& Total & 574 & 4.35 & 1.732 & & \\
\hdashline & Teachers & 422 & 4.43 & 1.911 & & 0.38 \\
\hdashline$-3 I I T 3$ & Assistants & 152 & 5.11 & 1.488 & 15.402 & $>.001$ & CI $=0.19-0.56$ \\
& Total & 574 & 4.61 & 1.832 & & & \\
\hline
\end{tabular}

Table 2. Differences between teachers and teaching assistants in Personal Innovativeness in the Domain of Information Technology.

Differences between teachers and teaching assistants are statistically significant for all three items (Table 2). It is clear that teaching assistants shows some higher levels of personal innovativeness; however, all effect sizes are in the small range. Based on the test results and calculated effect sizes, we cannot conclude that digital natives, which teaching assistants are supposed to be, are superior in PIIT.

To the best of our knowledge, there is no literature that would allow a comparison between university teachers, teaching assistants and students. There are only a few partial results in studies dealing with a single group (Table 3 ).

\begin{tabular}{|c|c|c|c|c|c|c|}
\hline Research & $\begin{array}{l}\text { Sample } \\
\text { size }\end{array}$ & Topic & Participants & PIIT 1 & PIIT 2 & PIIT 3 \\
\hline [22] & 388 & $\begin{array}{l}\text { Adoption of } \\
\text { wireless Internet } \\
\text { services } \\
\text { via mobile } \\
\text { technology }\end{array}$ & $\begin{array}{l}\text { MBA students, } \\
\text { University of Texas }\end{array}$ & $\begin{array}{l}\text { Mean: } \\
5.11 \\
\text { SD: } \\
1.38\end{array}$ & $\begin{array}{l}\text { Mean: } \\
4.12 \\
\text { SD: } \\
1.74\end{array}$ & $\begin{array}{l}\text { Mean: } \\
4.89 \\
\text { SD: } \\
1.67\end{array}$ \\
\hline$[36]$ & 66 & $\begin{array}{l}\text { Acceptance of } \\
\text { electronic learning } \\
\text { systems }\end{array}$ & $\begin{array}{l}3^{\text {rd }} \text { - and } 4^{\text {th }}-\text { year } \\
\text { graduate university } \\
\text { students Madrid }\end{array}$ & $\begin{array}{l}\text { Mean: } \\
4.81 \\
\text { SD: } \\
1.41\end{array}$ & $\begin{array}{l}\text { Mean: } \\
5.86 \\
\text { SD: } \\
1.22\end{array}$ & l \\
\hline [37] & 292 & $\begin{array}{l}\text { Mobile learning } \\
\text { acceptance }\end{array}$ & $\begin{array}{l}\text { undergraduate students } \\
\text { at a Chinese university }\end{array}$ & $\begin{array}{l}\text { Mean: } \\
3.85 \\
\text { SD: } \\
1.32\end{array}$ & $\begin{array}{l}\text { Mean: } \\
3.57 \\
\text { SD: } \\
1.25\end{array}$ & $\begin{array}{l}\text { Mean: } \\
3.05 \\
\text { SD: } \\
1.35 \\
\end{array}$ \\
\hline [38] & 175 & $\begin{array}{l}\text { Technology } \\
\text { acceptance }\end{array}$ & $\begin{array}{l}\text { business professionals } \\
\text { enrolled in a part-time } \\
\text { MBA program at a } \\
\text { comprehensive } \\
\text { university. }\end{array}$ & $\begin{array}{l}\text { Mean: } \\
5.46 \\
\text { SD: } \\
1.18\end{array}$ & $\begin{array}{l}\text { Mean: } \\
4.68 \\
\text { SD: } \\
1.53\end{array}$ & $\begin{array}{l}\text { Mean: } \\
5.58 \\
\text { SD: } \\
1.27\end{array}$ \\
\hline [39] & 121 & $\begin{array}{l}\text { Resistance to } \\
\text { Change and } \\
\text { technology } \\
\text { acceptance }\end{array}$ & $\begin{array}{l}\text { Students and users of } \\
\text { library of a university } \\
\text { in northeastern US }\end{array}$ & $\begin{array}{l}\text { Mean: } \\
5.05 \\
\text { SD: } \\
1.30\end{array}$ & $\begin{array}{l}\text { Mean: } \\
4.09 \\
\text { SD: } \\
1.30\end{array}$ & $\begin{array}{l}\text { Mean: } \\
4.79 \\
\text { SD: } \\
1.31\end{array}$ \\
\hline [40] & 264 & $\begin{array}{l}\text { Airline passengers' } \\
\text { continuance } \\
\text { intention towards } \\
\text { online check-in } \\
\text { services }\end{array}$ & airline users in China & $\begin{array}{l}\text { Mean: } \\
3.55 \\
\text { SD: } \\
0.95\end{array}$ & $\begin{array}{l}\text { Mean: } \\
3.57 \\
\text { SD: } \\
0.86\end{array}$ & $\begin{array}{l}\text { Mean: } \\
3.58 \\
\text { SD: } \\
0.87\end{array}$ \\
\hline [41] & 301 & $\begin{array}{l}\text { Intention To Use } \\
\text { Wireless Internet } \\
\text { Using Mobile } \\
\text { Devices }\end{array}$ & $\begin{array}{l}\text { mobile phone users } \\
\text { residing in the Klang } \\
\text { Valley. Kuala Lumpur }\end{array}$ & \multicolumn{3}{|c|}{$\begin{array}{l}\text { Combined Mean: } 3.12 \\
\text { Combined SD: } 0.67\end{array}$} \\
\hline
\end{tabular}

Table 3. Results of studies regarding Personal innovativeness in higher education. 
We reviewed 87 papers from the Web of Science containing the keywords Personal Innovativeness and student and 28 papers containing the keywords Personal Innovativeness and higher education. We searched for the construct PIIT and associated data; however, there was a huge lack of information and data in the literature review of results. These are missing either basic statistical data for the constructs or an appendix with the questions used for constructs; therefore, we found only 3 papers where all the data for the construct was accessible (Table 3 ). The sample population from all reviewed papers comprised university students. If we expand the search outside of higher education, we run into the same problem. It seems that authors usually do not include basic statistical data for the constructs and sometimes do not include an appendix with the questions used for the constructs, however, there are some studies that include both. Comparing our students with the results of other studies, we can see that as a cohort there are higher-positioned postsecondary institutions [22,36,38,39] and some lower-positioned ones [37], however, to obtain definitive answers, an international study with the same inventory should be conducted. We do not have a reference point for university professors and adjunct professors.

\section{Conclusion}

From the results retrieved, it was possible to draw several conclusions. The first and most important was that the average perceived PIIT for teachers and students falls around the middle of the seven-point scale, which cannot be regarded as a plausible predictor of upgrading the University into an Innovative Ecosystem. The second was that University teachers scored higher than their students, a situation that can produce an expectancy conflict between those who would like to work in an innovative way and those who would prefer studying by the book. There is a difference between university students and teachers in Personal Innovativeness in adoption of and experimentation with information technology, however the effect sizes fall on the border between small and medium.

Teaching assistants, who should logically belong to the generation of digital natives, are only slightly better at PIIT than university teachers, who can be regarded as digital immigrants. The difference between university teachers and their teaching assistants in Personal Innovativeness in adoption of and experimentation with information technology regarding effect size is small.

Based on raw data and lack of reference cut-off points we can only speculate that innovativeness in students and educators follows well known 80/20 Pareto principle [42] as observed in different domains of application of software $[43,44,45,46]$ but not by use of the comparative measurement tools [47], however, we can recognize that innovativeness and creativity are scarce even at the university. 


\section{Acknowledgements}

The authors acknowledge the help of Dr Michelle Gadpaille in polishing the language. The authors would like to thank the students and teachers who have been involved in the research, without whom this work would not have been possible.

\section{Funding details}

This work was supported by the Slovenian Research Agency under the core projects: "Computationally intensive complex systems", grant no. P1-0403 (Ploj Virtič, Mateja), and "Information systems", grant no. P2-0057 (Šorgo, Andrej).

\section{Declaration of Interest statement}

The authors declare that they have no conflict of interest.

The article is an original work of all the authors, and has not been submitted elsewhere, nor is it under consideration for publication in any other journal.

\section{References}

[1] B. Dobrowolska, "School Culture - Teacher's Competence - Students' Creative Attitudes", Reflection on school pragmatics. New Educational Review, vol. 20, no. 1, pp. 183-192, 2010.

[2] R. Florida, “America's looming creativity crisis", Harvard Business Review, vol. 82, no. 10, pp. 122-131, 2004.

[3] A. Šorgo, "Scientific creativity: The missing ingredient in Slovenian science education", European Journal of Educational Research, vol. 1, no. 2, 127-141, 2012.

[4] H. Segal, "Imagination, play and art," Unconscious Phantasy, pp. 211221, 2018.

[5] M. Mazzone and A. Elgammal, "Art, Creativity, and the Potential of Artificial Intelligence," Arts, vol. 8, no. 1, p. 26, 2019.

[6] K. Matsuura, "Appendix I UNESCO Universal Declaration on Cultural Diversity UNESCO Universal Declaration on Cultural Diversity," Diogenes, vol. 52, no. 1, pp. 141-145, 2005.

[7] N. A. Thompson, "Imagination and Creativity in Organizations," Organization Studies, vol. 39, no. 2-3, pp. 229-250, 2017.

[8] J. Alves, M. J. Marques, I. Saur, and P. Marques, "Creativity and Innovation through Multidisciplinary and Multisectoral Cooperation," Creativity and Innovation Management, vol. 16, no. 1, pp. 27-34, 2007. 
[9] M. A. West, "Sparkling Fountains or Stagnant Ponds: An Integrative Model of Creativity and Innovation Implementation in Work Groups," Applied Psychology, vol. 51, no. 3, pp. 355-387, 2002.

[10] D. J. Jackson, "What is an innovation ecosystem?”, National Science Foundation, vol. 1, no. 2, 2011.

[11] R. W. Weisberg, "Creativity and Knowledge: A Challenge to Theories," Handbook of Creativity, pp. 226-250, 1998.

[12] M. J. Kirton, "Adaptors and innovators: A description and measure”, Journal of Applied Psychology, vol. 61, pp. 622 - 629, 1976.

[13] R. J. Sternberg, “Creativity or creativities?” International Journal of Human-Computer Studies, vol. 63, no. 4-5, pp. 370 - 382, 2005.

[14] E. McWilliam, S. Dawson, "Teaching for creativity: towards sustainable and replicable pedagogical practice", Higher Education, vol. 56, no. 6, pp. 633-643, 2008.

[15] R. Agarwal, J. Prasad, "A conceptual and operational definition of personal innovativeness in the domain of information technology", Information Systems Research, vol. 9, no. 2, pp. 204-215, 1998.

[16] J. J. Ballor and V. V. Claar, "Creativity, innovation, and the historicity of entrepreneurship," Journal of Entrepreneurship and Public Policy, vol. 8, no. 4, pp. 513-522, 2019.

[17] M. Prensky, "Digital natives, digital immigrants", On the Horizon, vol. 9, no. 5, 2001.

[18] P. A. Kirschner and J. J. G. van Merriënboer, "Do Learners Really Know Best? Urban Legends in Education," Educational Psychologist, vol. 48, no. 3, pp. 169-183, 2013.

[19] A. Šorgo, T. Bartol, D. Dolničar, B. Boh Podgornik, “Attributes of digital natives as predictors of information literacy in higher education", British Journal of Educational Technology, vol. 48, no. 3, pp. 749-767, 2017.

[20] I. Sahin, "Detailed review of Rogers' diffusion of innovations theory and educational technology-related studies based on Rogers' theory", Turkish Online Journal of Educational Technology-TOJET, vol. 5, no. 2, 2006.

[21] G. Dambiski Gomes de Carvalho, J. Alisson Westarb Cruz, H. Gomes de Carvalho, L. Carlos Duclós, and R. de Fátima Stankowitz, "Innovativeness measures: a bibliometric review and a classification proposal," International Journal of Innovation Science, vol. 9, no. 1, pp. 81-101, 2017.

[22] J. Lu, J.E. Yao, C.S. Yu, "Personal innovativeness, social influences and adoption of wireless Internet services via mobile technology", The Journal of Strategic Information Systems, vol. 14, no. 3, pp. 245-268, 2005. 
[23] M. Dalvi-Esfahani, L. Wai Leong, O. Ibrahim, M. Nilashi, "Explaining Students' Continuance Intention to Use Mobile Web 2.0 Learning and Their Perceived Learning: An Integrated Approach", Journal of Educational Computing Research, vol. 57, no. 8, pp. 1956-2005, 2018.

[24] M. Shorfuzzaman, M. Alhussein, “Modeling Learners' Readiness to Adopt Mobile Learning: A Perspective from a GCC Higher Education Institution”, Mobile Information Systems, 2016, pp. 1-10, 2016.

[25] I. Milošević, D. Živković, D. Manasijević, D. Nikolić, "The effects of the intended behavior of students in the use of M-learning", Computers in Human Behavior, vol. 51, pp. 207-215, 2015.

[26] A. Šorgo, V. Lamanauskas, S.Š. Šašić, M. Kubiatko, P. Prokop, J. Fančovičova, M. Erdogan, "A cross-national study of prospective elementary and science teachers' creativity styles", Journal of Baltic Science Education, vol. 11, pp. 285-292, 2012.

[27] 1KA open-source application for web surveys [online]. Avaiable: https://www.1ka.si. [Accessed Feb. 25, 2021]

[28] W. Lewis, R. Agarwal, V. Sambamurthy, "Sources of influence on beliefs about information technology use: An empirical study of knowledge workers", MIS quarterly, pp. 657-678, 2003.

[29] B. Šumak, M. Pušnik, M. Heričko, A. Šorgo, "Differences between prospective, existing, and former users of interactive whiteboards on external factors affecting their adoption, usage and abandonment", Computers in Human Behavior, vol. 72, pp. 733-756, 2017.

[30] M. Y. Yi, J. D. Jackson, J. S. Park, J. C. Probst, “Understanding information technology acceptance by individual professionals: Toward an integrative view" Information \& Management, vol. 43, no. 3, pp. 350-363, 2006.

[31] A. Serenko, "A model of user adoption of interface agents for email notification", Interacting with Computers, vol. 20, no. 4-5, pp. 461-472, 2008.

[32] N. J. Taylor, "Public grid computing participation: An exploratory study of determinants", Information \& Management, vol. 44, no. 1, pp. 12-21, 2007.

[33] A. Herrero Crespo, I. A. Rodríguez Del Bosque Rodríguez, "Explaining B2C e-commerce acceptance: An integrative model based on the framework by Gatignon and Robertson", Interacting with Computers, vol. 20, no. 2, pp. 212-224, 2008.

[34] A. Field, “Discovering Statistics Using SPSS. 3rd Edition”, Sage Publications Ltd, 2009. 
[35] S. S. Sawilowsky, "New effect size rules of thumb", Journal of Modern Applied Statistical Methods, vol. 8, no. 2, pp. 597 - 599, 2009.

[36] A. F. Agudo-Peregrina, A. Hernández-García, F. J. Pascual-Miguel, "Behavioral intention, use behavior and the acceptance of electronic learning systems: Differences between higher education and lifelong learning", Computers in Human Behavior, vol. 34, pp. 301-314, 2014.

[37] S. Hao, V. P. Dennen, L. Mei, "Influential factors for mobile learning acceptance among Chinese users", Educational Technology Research and Development, vol. 65, no. 1, pp. 101-123, 2016.

[38] R. Agarwal, \& J. A. Prasad, "Conceptual and Operational Definition of Personal Innovativeness in the Domain of Information Technology", Information Systems Research, vol. 9, no. 2, pp. 204-215, 1998.

[39] O. Nov and C. Ye, "Personality and Technology Acceptance: Personal Innovativeness in IT, Openness and Resistance to Change," Proceedings of the 41st Annual Hawaii International Conference on System Sciences (HICSS 2008), 2008, pp. 448-448, 2008.

[40] Z. Lin and R. Filieri, “Airline passengers' continuance intention towards online check-in services: The role of personal innovativeness and subjective knowledge", Transportation Research Part E: Logistics and Transportation Review, vol. 81, pp. 158-168, 2015.

[41] F. Parveen and A. Sulaiman, “Technology Complexity, Personal Innovativeness And Intention To Use Wireless Internet Using Mobile Devices In Malaysia", International Review of Business Research Papers, vol. 4, no. 5, pp. 1-10, 2015.

[42] R. Sanders, "THE PARETO PRINCIPLE: ITS USE AND ABUSE," Journal of Services Marketing, vol. 1, no. 2, pp. 37-40, 1987.

[43] M. Goeminne and T. Mens, "Evidence for the pareto principle in open source software activity", Joint Porceedings of the 1st International workshop on Model Driven Software Maintenance and 5th International Workshop on Software Quality and Maintainability, pp. 74-82, 2011.

[44] K. Deb, "Unveiling innovative design principles by means of multiple conflicting objectives," Engineering Optimization, vol. 35, no. 5, pp. 445470, Oct. 2003.

[45] M. Magni, M. Susan Taylor, and V. Venkatesh, “'To play or not to play': A cross-temporal investigation using hedonic and instrumental perspectives to explain user intentions to explore a technology," International Journal of Human-Computer Studies, vol. 68, no. 9, pp. 572$588,2010$. 
[46] V. Ivančić, "Improving the decision making process through the Pareto principle application", Economic Thought and Practice, no. 2, pp. 633 656, 2016.

[47] G. Dambiski Gomes de Carvalho, J. Alisson Westarb Cruz, H. Gomes de Carvalho, L. Carlos Duclós, and R. de Fátima Stankowitz, "Innovativeness measures: a bibliometric review and a classification proposal," International Journal of Innovation Science, vol. 9, no. 1, pp. 81-101, 2017. 